\title{
Panorama nacional de perspectivas docentes para melhoria do ensino de Ciências
}

\section{na Educação Básica}

\author{
National panorama about teaching perspectives for improving Science teaching in Basic Education \\ Panorama nacional de perspectivas docentes para mejorar la enseñanza de las Ciencias en la
}

Educación Básica

Recebido: 25/10/2021 | Revisado: 04/11/2021 | Aceito: 06/11/2021 | Publicado: 10/11/2021

\author{
Karine Gehrke Graffunder \\ ORCID: https://orcid.org/0000-0001-8860-9889 \\ Universidade Federal de Santa Maria, Brasil \\ E-mail: kagraffunder@gmail.com \\ Cíntia Moralles Camillo \\ ORCID: https://orcid.org/0000-0003-2876-9156 \\ Universidade Federal de Santa Maria, Brasil \\ E-mail: cintiacamillo@gmail.com
}

\begin{abstract}
Resumo
Diante de um cenário frágil, em que 'todo mundo' tem um palpite certeiro para resolver os problemas do ensino, divulgar a opinião dos educadores se faz essencial. Este estudo tem por objetivo investigar e analisar 64 perspectivas docentes (45 mulheres e 19 homens), com faixa etária entre 23 e 58 anos, para melhoria do ensino de Ciências na Educação Básica do Brasil. De natureza investigativa e de caráter qualitativo, esse estudo ocorreu a partir da elaboração, aplicação e análise de um questionário semiestruturado para professores que estão atuando na regência da disciplina de Ciências Naturais do $9^{\circ}$ ano de escolas da Educação Básica do Brasil. Foram estabelecidas as categorias de análise: (1) Formação inicial e continuada de professores; (2) Estrutura e recursos escolares; e (3) Currículo. Participaram da pesquisa professores de 14 estados do Brasil, totalizando representantes das cinco regiões do país, os quais possuem uma ou mais de uma graduação em Ciências Biológicas, Matemática, Química e Pedagogia. Os docentes sugeriram reformular a formação inicial do professor, implementando disciplinas ligadas às tecnologias; e abordaram a necessidade de formação continuada relacionada às atividades experimentais, tanto para sensibilização, elaboração e realização destas em laboratórios. Outrossim, descrevem inquietudes sobre a responsabilidade do aluno perante o seu aprendizado e a falta do acompanhamento familiar; além da acomodação de alguns profissionais na prática docente. Por fim, concluímos que o professor é parte do processo de construção de uma sociedade mais humana e justa. E por isso, deve ser mais valorizado.
\end{abstract}

Palavras-chave: Ciências naturais; Formação de professores; Mudanças curriculares; Políticas públicas.

\begin{abstract}
Faced with a fragile scenario, in which 'everyone' has an accurate hunch to solve teaching problems, disseminating the opinion of educators is essential. This study aims to investigate and analyze 64 teaching perspectives (45 women and 19 men), aged between 23 and 58 years, to improve the teaching of Science in Basic Education in Brazil. With an investigative and qualitative nature, this study took place through the elaboration, application and analysis of a semistructured questionnaire for teachers who are acting in the course of the Natural Sciences discipline of the 9th grade of Basic Education schools in Brazil. The categories of analysis were established: (1) Initial and continuing teacher education; (2) School structure and resources; and (3) Curriculum. Professors from 14 Brazilian states participated in the research, totaling representatives from the five regions of the country, who have one or more degrees in Biological Sciences, Mathematics, Chemistry and Pedagogy. The professors suggested to reformulate the initial formation of the professor, implementing disciplines related to technologies; and addressed the need for continuing education related to experimental activities, both for awareness, development and implementation of these in laboratories. Furthermore, they describe concerns about the student's responsibility towards their learning and the lack of family support; in addition to the accommodation of some professionals in teaching practice. Finally, we conclude that the teacher is part of the process of building a more humane and just society. And for that, it should be more valued.
\end{abstract}

Keywords: Natural sciences; Teacher training; Curriculum changes; Public policy.

\section{Resumen}

Ante un escenario frágil, en el que 'todos' tienen una corazonada acertada para resolver los problemas de la enseñanza, difundir la opinión de los educadores es fundamental. Este estudio tiene como objetivo investigar y analizar 64 perspectivas docentes (45 mujeres y 19 hombres), con edades entre 23 y 58 años, para mejorar la enseñanza de las 
Ciencias en la Educación Básica en Brasil. Con carácter investigativo y cualitativo, este estudio se llevó a cabo mediante la elaboración, aplicación y análisis de un cuestionario semiestructurado para docentes que se encuentran actuando en la carrera de Ciencias Naturales en el noveno grado de las escuelas de Educación Básica en Brasil. Se establecieron las categorías de análisis: (1) Formación docente inicial y continua; (2) Estructura y recursos escolares; y (3) plan de estudios. En la investigación participaron docentes de 14 estados de Brasil, totalizando representantes de las cinco regiones del país, quienes tienen una o más titulaciones en Ciencias Biológicas, Matemáticas, Química y Pedagogía. Los profesores sugirieron reformular la formación inicial del profesor, implementando disciplinas relacionadas con las tecnologías; y abordó la necesidad de educación continua relacionada con las actividades experimentales, tanto para la sensibilización, desarrollo e implementación de estas en los laboratorios. Además, describen preocupaciones sobre la responsabilidad del estudiante hacia su aprendizaje y la falta de apoyo familiar; además del alojamiento de algunos profesionales en la práctica docente. Finalmente, concluimos que el docente es parte del proceso de construcción de una sociedad más humana y justa. Y por eso debería ser más valorado.

Palabras clave: Ciencias naturales; Formación de profesores; Cambios curriculares; Políticas públicas.

\section{Introdução}

O século XXI tem sido marcado pela avaliação e consolidação de experiências de popularização da Ciência, tanto no Brasil como em vários países latino-americanos, as quais ainda necessitam de maior alcance entre os indivíduos da sociedade (Krasilchik \& Marandino, 2007). No campo educacional, apesar dos esforços de renovação existentes, o ensino de Ciências ainda permanece baseado na transmissão de informações, em aulas expositivas e no livro didático como principal recurso pedagógico (Menezes, 2000).

As novas demandas da reforma educacional, a deterioração do clima educacional, especialmente nos anos finais do Ensino Fundamental e Médio, e o desajuste crescente entre as metas dos professores e as dos alunos são alguns dos indícios mais presentes e inquietantes da atual crise da educação científica (Pozo \& Crespo, 2009). Entre as implicações desse processo estão, por exemplo, a falta de interesse dos alunos no trabalho científico, assumindo posições passivas no exercício da Ciência (Krasilchik, 2004).

Alvarez (2017) afirma que faltam políticas gerais de valorização da Ciência e, o fundamentalismo religioso também atrapalha. Outro ponto que pesa contra é o estereótipo do cientista maluco. Para completar a lista, as inovações no ensino de Ciências não chegam às escolas de Educação Básica por deficiências na infraestrutura, na formação docente e na falta de boas perspectivas de carreira docente, males que acometem a educação brasileira em qualquer disciplina. Mól (2020) indica que tudo isso nos remete à necessidade de promover a reflexão sobre o ensino e a formação do professor de Ciências.

Lovato, Michelotti e Loreto (2018) afirmam que mudanças sociais têm levado a mudanças de percepção no processo de ensino-aprendizagem, levando ao surgimento das chamadas 'metodologias ativas de aprendizagem'. Nessas metodologias, o aluno torna-se o protagonista central. Suas aplicações permitem o desenvolvimento de novas competências, como a iniciativa, a criatividade, a criticidade reflexiva, a capacidade de autoavaliação e a cooperação para se trabalhar em equipe. Desse modo, o professor atua como orientador, supervisor e facilitador do processo.

Conhecer as ciências tem, portanto, um alto grau de comprometimento com a percepção de que o mundo está em constante modificação, sendo importante e necessária a permanente busca por construir entendimento acerca de novas formas de conceber os fenômenos naturais e os impactos que estes têm sobre nossa vida. Assim pensando, a alfabetização científica deve desenvolver em uma pessoa qualquer a capacidade de organizar seu pensamento de maneira lógica, além de auxiliar na construção de uma consciência mais crítica em relação ao mundo que a cerca (Sasseron, 2011; Sasseron 2015). Para Wilson et al. (2013), realizar o trabalho inicial com professores é a estratégia central para se alcançar um efeito multiplicador: de professores alfabetizados em termos informacionais para seus alunos e, eventualmente, para a sociedade em geral.

Diante de um cenário frágil, em que ‘todo mundo’ tem um palpite certeiro, uma dica mágica, ou uma receita infalível para resolver os problemas do ensino, divulgar a opinião dos educadores se faz essencial. Ser pioneiro de mudanças e protagonista desse processo é participar da busca por soluções. Desse modo, este estudo tem por objetivo investigar e analisar 
64 perspectivas docentes para melhoria do ensino de Ciências na Educação Básica do Brasil.

\section{Metodologia}

Uma pesquisa pode ser classificada em relação à sua natureza, aos objetivos, à abordagem do problema e aos procedimentos técnicos adotados (Gil, 2010). De natureza investigativa e de caráter qualitativo, esse estudo ocorreu a partir da elaboração, aplicação e análise de um questionário semiestruturado pelas pesquisadoras. A amostragem é aleatória e não probabilística intencional.

A primeira etapa referiu-se à coleta de informações pessoais como idade, sexo, estado em que o participante reside e área de formação. Já a segunda etapa solicitou aos participantes responder a seguinte questão: 'Se você pudesse solucionar dois problemas no Ensino de Ciências, o que você iria propor/mudar'?

O questionário foi elaborado para professores que estão atuando na regência da disciplina de Ciências Naturais do $9^{\circ}$ ano de escolas da Educação Básica do Brasil. A aplicação ocorreu de forma virtual em nove grupos de professores da rede social Facebook, entre os meses de maio a junho de 2021.

Os dados numéricos obtidos apresentam o perfil dos participantes da pesquisa, e os elementos textuais foram interpretados por meio da análise de conteúdo, conforme os pressupostos orientados/defendidos por Laurence Bardin (Bardin, 2011). Segundo Bardin (2011), a análise de conteúdo é utilizada para ressaltar as palavras, frases e expressões dentro de um texto ou de vários outros textos, possibilitando o enriquecimento na leitura dos dados coletados. Assim, a análise é dividida em três fases distintas: a pré-análise, a descrição analítica e a interpretação.

As seguintes categorias de análise foram determinadas: (1) Formação inicial e continuada de professores; (2) Estrutura e recursos escolares; e (3) Currículo. A identidade dos sujeitos participantes da pesquisa foi mantida em sigilo e identificados na análise por letras do alfabeto. Para elucidar o passo a passo da presente pesquisa, foi sistematizado um esquema organizacional, o qual é apresentado a seguir (Figura 1).

Figura 1. Etapas da metodologia adotada para esse estudo.
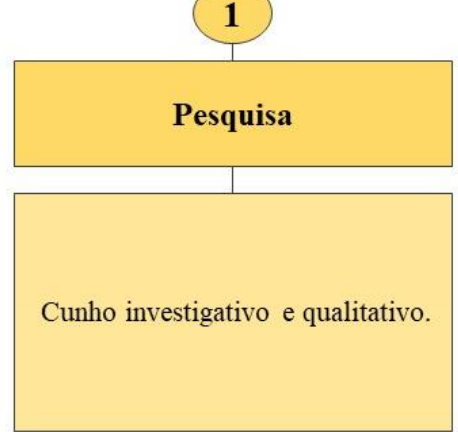

4

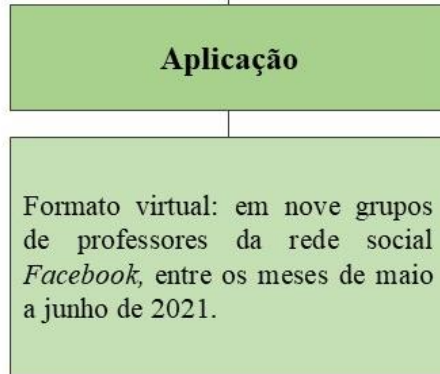

2

Elaboração de um questionário semiestruturado

$1^{\circ}$ etapa: Coleta de informações.

$2^{\circ}$ - Responder à questão: 'Se você pudesse solucionar dois problemas no Ensino de Ciências, o que você iria propor/mudar'?

\section{5}

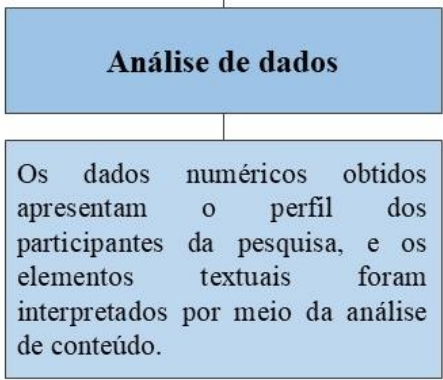

3

Público-alvo

Professores que estão atuando na regência da disciplina de Ciências Naturais do $9^{\circ}$ ano de escolas da Educação Básica do Brasil.
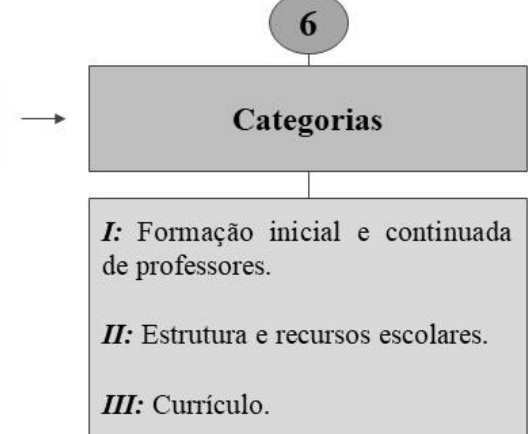

Fonte: Autores. 


\section{Resultados e Discussão}

O questionário foi respondido por 64 professores (45 mulheres e 19 homens), com faixa etária entre 23 e 58 anos. Participaram da pesquisa professores de 14 estados do Brasil, conforme o Quadro 1.

Quadro 1. Região e estado que pertencem os professores da pesquisa.

\begin{tabular}{|c|c|c|c|}
\hline \multirow{2}{*}{ Região } & Estado & $\begin{array}{c}\text { Número de } \\
\text { participantes }\end{array}$ & $\begin{array}{c}\text { Valor em } \\
\text { porcentagem }\end{array}$ \\
\hline \multirow{3}{*}{ Centro-Oeste } & Mato Grosso do Sul & 10 & $15,6 \%$ \\
\cline { 2 - 4 } & Mato Grosso & 2 & $3,1 \%$ \\
\hline \multirow{3}{*}{ Nordeste } & Bahia & 4 & $6,2 \%$ \\
\cline { 2 - 4 } & Ceará & 1 & $1,6 \%$ \\
\cline { 2 - 4 } & Piauí & 1 & $1,6 \%$ \\
\hline \multirow{3}{*}{ Norte } & Pará & 6 & $9,3 \%$ \\
\cline { 2 - 4 } & Rondônia & 1 & $1,6 \%$ \\
\hline \multirow{3}{*}{ Sudeste } & Rio de Janeiro & 11 & $17,2 \%$ \\
\cline { 2 - 4 } & São Paulo & 9 & $14,1 \%$ \\
\cline { 2 - 4 } & Minas Gerais & 5 & $7,8 \%$ \\
\cline { 2 - 4 } & Espírito Santo & 1 & $1,6 \%$ \\
\hline \multirow{3}{*}{ Sul } & Rio Grande do Sul & 7 & $10,9 \%$ \\
\cline { 2 - 4 } & Paraná & 3 & $4,7 \%$ \\
\cline { 2 - 4 } & Santa Catarina & 3 & $4,7 \%$ \\
\hline \multirow{2}{*}{ Dados finais } & 64 & $100 \%$ \\
\hline
\end{tabular}

Fonte: Autores.

Desse modo, sinaliza-se que houve representantes das cinco regiões do país: 26 professores do Sudeste $(40,6 \%), 13$ do Sul (20,3\%), 12 do Centro-Oeste (18,8\%), sete do Norte (10,9\%) e seis do Nordeste $(9,4 \%)$. Embora acreditamos que se tenha obtido uma boa amostragem nesse estudo, e em conformidade com Morin et al. (2020), pode-se atribuir o baixo número de participantes em função da falta de tempo dos sujeitos ou ausência de hábito/experiência/interesse em participar de pesquisas.

Em seu estudo, Graffunder et al. (2020) analisaram 32 trabalhos de três edições (2015, 2017 e 2019) do Encontro Nacional de Pesquisa em Educação em Ciências (ENPEC), sobre as contribuições, avanços e/ou fragilidades de ações pedagógicas relacionadas à Alfabetização Científica (AC) no Ensino de Ciências (EC) da Educação Básica. Como resultado, as autoras verificaram que a região Sudeste, além de ser a que possuiu maior representatividade nos trabalhos, têm se mantido estável no decorrer das três últimas edições em termos de pesquisas nesta linha temática. Embora as outras regiões, Norte e Sul apresentarem um percentual semelhante, notou-se um incremento de pesquisas para esta linha de pesquisa na região Sul, o que difere em relação ao Norte do país, em que se evidenciou uma queda significativa das pesquisas na área.

Praticamente a mesma situação se repetiu no presente estudo, o que indica o quanto ainda há para ser construído na área. Em relação à formação, os professores possuem uma ou mais de uma graduação em Ciências Biológicas, Matemática, Química e Pedagogia - áreas específicas para o ensino de Ciências Naturais do $9^{\circ}$ ano nas escolas brasileiras. A seguir, descrevemos sobre as três categorias adotadas na análise de conteúdo.

\subsection{Formação inicial e continuada de professores}

Os participantes destacaram que é essencial que ocorra mudanças na formação inicial dos docentes, ressaltando que: 
(A) "Iria propor uma reformulação na licenciatura. O curso acadêmico deveria capacitar os futuros profissionais nos conhecimentos básicos das áreas de ciências da Natureza, já que o currículo atual dos anos finais abrange as três áreas das ciências da natureza conforme a BNCC”.

(B) "Mudar a formação inicial do professor implementando disciplinas ligadas as tecnologias e disciplinas que fossem mais práticas, considerando o cotidiano do professor e do aluno".

Discute-se hoje na literatura especializada sobre formação docente, a ideia do desenvolvimento profissional dos professores como uma concepção de formação não dissociada da própria realização do trabalho docente. Sendo assim, segundo Diniz-Pereira, Flores e Fernandes (2021), ao discutir a formação dita "inicial" ou a formação dita "continuada" de professores, não poderíamos nos esquecer do princípio da indissociabilidade entre a formação e as condições adequadas para a realização do trabalho docente. Os autores citam a necessidade de haver salários dignos; maior autonomia profissional; dedicação exclusiva a uma única escola; pelo menos um terço da jornada de trabalho para planejamento; reflexão e sistematização da prática; estudos individuais e coletivos; e salas de aula com um número reduzido de alunos.

Em face das evidências, é de suma importância a atuação do professor frente a todos os aspectos da ação e do processo pedagógico. Para Camillo, Graffunder e Sepel (2021) investir em cursos de formação complementar o auxilia a atingir os objetivos almejados, diante de áreas distintas que precisa articular. Ademais, aprende a desenvolver aulas mais atrativas, contextualizadas e integradoras.

Acerca da formação continuada, foi identificado temas emergentes como o uso de tecnologias e como aplicar de forma prática a Base Nacional Curricular Comum (BNCC) no dia a dia escolar. Isso também envolve aplicar diferentes metodologias em sala de aula.

\section{(C) "Formação continuada e praticar a BNCC de fato". \\ (D) "Cursos de formação para professores na área de tecnologias".}

Santos et al. (2021) refletem sobre a cultura digital no âmbito da BNCC, considerando as competências e habilidades que estão sendo direcionadas para os alunos e como isso poderá repercutir na prática docente. Como resultado, perceberam um maior engajamento do sistema educacional brasileiro para o desenvolvimento da cultura digital, entretanto, os documentos em si não problematizam a necessidade de instrução com formação para os docentes lidarem com o digital na sala de aula.

Nesse contexto, Camillo e Graffunder (2021) apresentam algumas possibilidades com o uso dos multimeios com as Tecnologias Digitais de Informação e Comunicação (TDIC), para que o professor possa explorar e utilizar em seus planejamentos didáticos. Alguns exemplos são as Videoconferências na Educação; Ambientes Virtuais de Ensino e Aprendizagem; Mural interativo; Apresentações dinâmicas e interativas; Formulários; Mapas mentais e Mapas conceituais; Infográficos; Nuvens de palavras; e Criação de Sites e Blogs.

A Base, como um documento norteador da Educação Básica, prevê o uso de tecnologias em sala de aula. Todavia, um desafio para as escolas consiste na implementação efetiva desses recursos. Nesse contexto, a formação continuada é fundamental para que a escola acompanhe as novidades no contexto educacional e entenda como pode aprimorar sempre seus métodos, tornando-os cada vez mais assertivos.

\subsection{Estrutura e recursos escolares}

A implementação de laboratórios de Ciências e de Informática nas escolas foi solicitada por $22(34,4 \%)$ dos professores entre os 64 participantes. Alguns pedidos realizados foram: 
(E) "Laboratórios de Ciências nas escolas e Verbas para as escolas investirem em projetos de pesquisas".

(F) "Mais espaços para iniciação científica na educação básica".

(G) "Mais laboratórios de Ciências e materiais para estes, assim como laboratórios de tecnologias".

As atividades práticas e experimentais têm sua relevância, principalmente, por possibilitarem a construção do conhecimento a partir de sua relação com o cotidiano dos alunos. Nesse sentido, o laboratório permite aprender a teoria na prática; ter experiência multidisciplinar; garantir a fixação do conteúdo; desenvolver o senso crítico; e aprender a trabalhar em equipe.

Em seus estudos, Santana et al. (2019) visitaram 35 escolas públicas das cidades de Barra do Quaraí e Uruguaiana, localizadas na fronteira oeste do Rio Grande do Sul (RS), abrangendo um público total de 1430 alunos, 46 professores da área e 37 gestores. A análise mostrou que apenas 16 escolas possuem laboratório de ciências, representando 45,7\%. Portanto, 19 escolas, totalizando 54,3\% estão sem laboratório. Destas, cinco oferecem o Ensino Médio, o que representa cerca de $26 \%$. Sobre o uso, dentre as que possuem, seis utilizam o espaço, com regularidade ou não, e cinco não o utilizam.

A partir desse estudo, concluímos que mais da metade das escolas públicas não possuem laboratórios. E quando presentes, as instalações de alguns são tão inadequadas que seria impossível abrigar turmas inteiras para uma aula de qualidade, inclusive por questão de segurança. Contudo, naquelas cujo espaço é disponibilizado e a aula poderia ser ministrada com tranquilidade e bom aproveitamento, o uso efetivo não só é raro como não existe. Existe assim, a necessidade de formação continuada relacionada às atividades experimentais, tanto para sensibilização, quanto para elaboração e realização destas atividades.

\subsection{Currículo}

Durante a análise das respostas, identificamos que os professores também buscam por mudanças curriculares, em carga horária, abordagem metodológica e nos papeis exercidos pelo professor e aluno nos processos de ensino e aprendizagem. Discorrem:

(H) “A falta de contextualização dos livros didáticos e a escassez de incentivo a pesquisa dos pequeninos".

(I) "Colocar as metodologias ativas como disciplina obrigatória no curso".

(J) “- Tirar o foco de conteúdos muito específicos que servem apenas para formular questões de vestibular e dar mais enfoque em questões cotidianas ou com efeitos mais relevantes. Exemplo: Muito mais importante que saber quantas cavidades tem o coração de um anfíbio ou réptil, o aluno deveria saber o papel ecológico e importâncias destes. Mas, como temos tantos conteúdos para passar, acaba não dando tempo para falar mais sobre coisas importantes e tudo fica muito superficial [..]".

Camillo, Graffunder e Sepel (2021) analisaram a presença da interdisciplinaridade e a contextualização nas atividades experimentais e exercícios presentes em livros didáticos da área de Ciências Naturais para o Ensino Fundamental. Das 123 questões analisadas, $87 \%$ apresentaram interdisciplinaridade e contextualização. Entretanto, é necessário ampliar o conceito da interdisciplinaridade no Ensino de Ciências para áreas distintas, uma vez que nenhum exercício dos livros didáticos retratou a História da Ciência, explorando datas, nomes e o contexto em que ocorreu a produção científica.

Conforme Moran (2015), as metodologias ativas "são pontos de partida para avançar para processos mais avançados de reflexão, de integração cognitiva, de generalização, de reelaboração de novas práticas". E complementa que "a melhor forma de aprender é combinando equilibradamente atividades, desafios e informação contextualizada." 
Por outro lado, os professores também abordaram inquietudes sobre a responsabilidade do aluno perante o seu aprendizado e a falta do acompanhamento familiar. Além disso, citam como problema a acomodação de alguns profissionais que não ousam no uso de metodologias diversificadas.

(K) "A aprovação de qualquer forma de alunos que não estudam de forma nenhuma e o sistema enlouquece os professores com suas fichas, formulários que o professor precisa justificar a não participação desse aluno, da sua família".

(L) "Não tem como ensinar quem não quer aprender isso tem desgastado e adoecido o professor que já não sabe mais o que tem que fazer, na faculdade aprendemos conceitos o porquê as coisas são assim e como é a sua fisiologia, Anatomia etc. Não aprendemos justificar por que o aluno não atingiu a habilidade necessária. E essa necessidade de justificar que o aluno não entrega suas atividades, que o aluno não tentou fazer nenhuma das várias propostas que você elaborou e pensou para ele, e quando você vai conversar para saber para ver se tem uma resposta o aluno responde que vai fazer que vai tentar que é para esperar. O que fazer? Eu não sei mais".

(M) "A grande quantidade de teoria sem prática na formação dos professores, e a preguiça que a maioria dos professores possuem em buscar algo realmente eficaz no Ensino de Ciências".

Realmente, os professores têm se sentido desmotivados, sobrecarregados, ansiosos e cansados. Soma-se a isso, o fato de que os educadores são frequentemente os primeiros a ser criticados e os últimos a receberem agradecimentos. $\mathrm{O}$ ano pandêmico pela COVID-19 não foi diferente. Passamos a conviver com algo sobre o qual não tínhamos controle. Até aqui, chegamos a ser criticados por pessoas que não têm especialização em Educação ou experiência em sala de aula. Apesar disso, o educador brasileiro que apresenta resiliência e persistência, se mostrou pronto e disposto a desempenhar seu papel com coragem e otimismo.

Segundo Morin e Diaz (2016, p. 32) "a consciência da complexidade leva a uma tomada de consciência da indispensável mudança de paradigma nas ciências, partindo de uma visão simplificadora, unidimensional e parcial, para um conhecimento multidimensional, integrado e complexo". Desse modo, a interdisciplinaridade relacionada à realidade concreta, histórica e cultural, requer trabalhar temas no ensino de Ciências de forma contextualizada, em que os alunos construam atitudes e habilidades como participação, autonomia e responsabilidade no processo de ensino aprendizagem (Cardoso et al., 2017).

A paciência, a didática, a criatividade e a motivação são aspectos importantes e que fazem a diferença na hora de ensinar. E, muito além das salas de aula, os saberes transmitidos por docentes fazem parte da construção social, cultural, cognitiva, afetiva e humana dos alunos. Assim, não há como falar em um mundo melhor para todas as pessoas sem mencionar a centralidade da formação do indivíduo, e isso ocorre por meio da Educação. Ou seja, o professor é parte do processo de construção de uma sociedade mais humana e justa. E por isso, deve ser mais valorizado.

\section{Considerações Finais}

Este estudo teve por objetivo investigar e analisar 64 perspectivas docentes ( 45 mulheres e 19 homens), com faixa etária entre 23 e 58 anos, para melhoria do ensino de Ciências na Educação Básica do Brasil. Participaram da pesquisa professores de 14 estados do Brasil, totalizando representantes das cinco regiões do país, os quais possuem um ou mais cursos em Ciências Biológicas, Matemática, Química e Pedagogia.

Os docentes sugeriram reformular a formação inicial do professor, implementando disciplinas ligadas às tecnologias; e abordaram a necessidade de formação continuada relacionada às atividades experimentais, tanto para sensibilização, 
elaboração e realização destas em laboratórios. Ressaltamos que a implementação de laboratórios de Ciências e de Informática nas escolas foi solicitada por $22(34,4 \%)$ dos professores entre os 64 participantes.

Aliás, identificamos que os professores também buscam por mudanças curriculares, em carga horária, abordagem metodológica e nos papeis exercidos pelo professor e aluno nos processos de ensino e aprendizagem. Descrevem inquietudes sobre a responsabilidade do aluno perante o seu aprendizado e a falta do acompanhamento familiar; além da acomodação de alguns profissionais na prática docente.

Realmente, os professores têm se sentido desmotivados, sobrecarregados, ansiosos e cansados. Soma-se a isso, o fato de que os educadores são frequentemente os primeiros a serem criticados e os últimos a receberem agradecimentos. Apesar disso, o educador brasileiro apresenta resiliência e persistência, se mostrando pronto e disposto a desempenhar seu papel com coragem e otimismo.

Enfim, pensar na Educação como a chave para o progresso do país significa pensar na valorização dos professores, seja nas salas de aula, seja fora delas. Acreditamos que para isso, o professor deve ser remunerado de forma adequada, receber os recursos necessários para realizar sua função e ter voz ativa na elaboração de políticas públicas, no que compete a esfera educacional.

Esperamos que os resultados desta pesquisa contribuam para direcionar a mudanças na educação científica do Brasil, no intuito de apresentar a percepção desta pelos atores de sua execução (professores). A pandemia pela COVID-19 trouxe essa discussão para outra dimensão. Além disso, a infraestrutura, e o acesso às ferramentas tecnológicas pelos professores e pelos estudantes são questões extremamente desafiadoras. Permanece, assim, um amplo espaço para se discutir como melhorar o ensino de Ciências através da capacitação e valorização dos professores; desenvolvimento das habilidades socioemocionais do aluno; inserção de tecnologias na sala de aula e educação para o mundo digital; múltiplas formas de aprendizado; e como se dará a educação infantil no pós-pandemia.

\section{Referências}

Alvarez, L. (2017). Ensino de ciências ainda sofre com desconexão entre disciplinas e falta de espaço para alunos criarem hipóteses. Revista Educação: https://revistaeducacao.com.br/2017/12/14/ensino-de-ciencias-ainda-sofre-com-desconexao-entre-disciplinas-e-falta-de-espaco-para-alunos-criaremhipoteses/.

Bardin, L. (2011). Análise de conteúdo. (2a ed.), Edições 70.

Camillo, C. M., Graffunder, K. G., \& Sepel, L. M. N. (2021). Análise da abordagem interdisciplinar e contextualizada na área de ciências naturais em livros didáticos do $9^{\circ}$ ano. Research, Society and Development, 10(11), e471101119905-e471101119905.

Camillo, C. M. \& Graffunder, K. G. (2021). O ensino e a aprendizagem por meio das tecnologias digitais e multimeios. Taurite. 54 p.

Cardoso, F. S., Motta, E. S., Castro, H. C. \& SÁ, S. R. A. N. (2017). A complexidade e a interdisciplinaridade: breves reflexões nos contextos histórico e atual do ensino. Revista Práxis, 9(18), 33-41.

Diniz-Pereira, J. E., Flores, M. J. B., \& Fernandes, F. S. (2021). Princípios gerais para a reforma dos cursos de licenciatura no Brasil. Interfaces da Educação, 12(34), 589-614.

Gil, A. C. (2010). Como elaborar projetos de pesquisa. (5a ed.) Atlas.

Graffunder, K. G., Camillo, C. M., Oliveira, N. M., \& Goldschmidt, A. I. (2020). Alfabetização científica e o ensino de Ciências na Educação Básica: panorama no contexto das pesquisas acadêmicas brasileiras nos últimos cinco anos de ENPEC. Research, Society and Development, 9(9), e313997122e313997122.

Lovato, F. L., Michelotti, A., \& da Silva Loreto, E. L. (2018). Metodologias ativas de aprendizagem: uma breve revisão. Acta Scientiae, 20(2), 1-18.

Krasilchik, M., \& Marandino, M. (2007). Cidadão e a Alfabetização Científica. Ensino de Ciências e Cidadania, 2.

Krasilchik, M. (2004). Prática de ensino de biologia. Edusp.

Menezes, L. D. (2000). Ensinar ciências no próximo século. O desafio de ensinar ciências no século XXI, 48-54.

Mól, G. S. (2020). A formação de professores de ciências: uma análise da sua atuação frente aos desafios e inovações do mundo moderno. Brazilian Journal of Development, 6(3), 15834-15845. 
Research, Society and Development, v. 10, n. 14, e475101422271, 2021

(CC BY 4.0) | ISSN 2525-3409 | DOI: http://dx.doi.org/10.33448/rsd-v10i14.22271

Moran, J. M. (2015) Mudando a educação com metodologias ativas. In: Souza, C. A., \& Torres-Morales, O. E. (orgs.). Convergências midiáticas, educação e cidadania: aproximações jovens. Ponta Grossa, PR: UEPG.

Morin, V. L., de Deus, G. B., Oliveira, N. M., Graffunder, K. G., \& Muenchen, C. (2020). Paulo Freire na atualidade: concepções de estudantes do programa de pós-graduação em educação em ciências: química da vida e saúde da UFSM. Vivências, 16(31), 171-178.

Morin, E., \& Diaz, C. (2016). Reinventar a educação: abrir caminhos para a metamorfose da humanidade. Palas Athena.

Pozo, J. I., \& Crespo, M. Á. G. (2009). A aprendizagem e o ensino de ciências: do conhecimento cotidiano ao conhecimento científico. Porto Alegre: Artmed, 5,5 .

Santana, S. D. L. C., Pessano, E. F. C., Escoto, D. F., da Cruz Pereira, G., Gularte, C. A. O., \& Folmer, V. (2019). O ensino de ciências e os laboratórios escolares no Ensino Fundamental. VITTALLE-Revista de Ciências da Saúde, 31(1), 15-26.

Santos, W. L., Fonseca, M. R., Alves, M. M. S., \& Rodrigues, B. M. (2021). Cultura digital e BNCC: contradições e desafios para a prática docente. Brazilian Journal of Development, 7(6), 55908-55921.

Sasseron, L. H., \& de Carvalho, A. M. P. (2011). Alfabetização científica: uma revisão bibliográfica. Investigações em ensino de ciências, 16(1), 59-77.

Sasseron, L. H. (2015). Alfabetização científica, ensino por investigação e argumentação: relações entre ciências da natureza e escola. Ensaio Pesquisa em Educação em Ciências (Belo Horizonte), 17, 49-67.

Wilson, C., Grizzle, A., Tuazon, R., Akyempong, K., \& Cheung, C. K. (2013). Alfabetização midiática e informacional: currículo para formação de professores. Unesco: UFTM. 